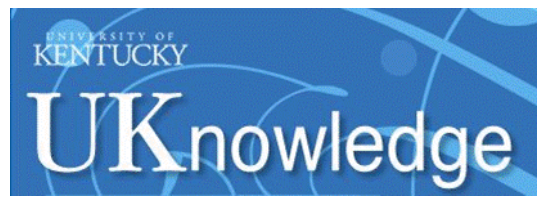

University of Kentucky

UKnowledge

$11-2019$

\title{
Optimal Combinations of Utility Level Renewable Generators for a Net Zero Energy Microgrid Considering Different Utility Charge Rates
}

\author{
Evan S. Jones \\ University of Kentucky, SEvanJones@uky.edu \\ Huangjie Gong \\ University of Kentucky, huangjie.gong@uky.edu \\ Dan M. Ionel \\ University of Kentucky, dan.ionel@uky.edu
}

Follow this and additional works at: https://uknowledge.uky.edu/peik_facpub

Part of the Power and Energy Commons

Right click to open a feedback form in a new tab to let us know how this document benefits you.

\section{Repository Citation}

Jones, Evan S.; Gong, Huangjie; and Ionel, Dan M., "Optimal Combinations of Utility Level Renewable Generators for a Net Zero Energy Microgrid Considering Different Utility Charge Rates" (2019). Power and Energy Institute of Kentucky Faculty Publications. 8.

https://uknowledge.uky.edu/peik_facpub/8

This Conference Proceeding is brought to you for free and open access by the Power and Energy Institute of Kentucky at UKnowledge. It has been accepted for inclusion in Power and Energy Institute of Kentucky Faculty Publications by an authorized administrator of UKnowledge. For more information, please contact UKnowledge@lsv.uky.edu. 


\title{
Optimal Combinations of Utility Level Renewable Generators for a Net Zero Energy Microgrid Considering Different Utility Charge Rates
}

\author{
Digital Object Identifier (DOI) \\ https://doi.org/10.1109/ICRERA47325.2019.8996529 \\ Notes/Citation Information \\ Published in 2019 8th International Conference on Renewable Energy Research and Applications \\ (ICRERA).
}

(C) 2018 IEEE Copyright Notice. "Personal use of this material is permitted. Permission from IEEE must be obtained for all other uses, in any current or future media, including reprinting/republishing this material for advertising or promotional purposes, creating new collective works, for resale or redistribution to servers or lists, or reuse of any copyrighted component of this work in other works."

The document available for download is the authors' manuscript version that is accepted for publication. The final published version is copyrighted by IEEE and will be available as: E. S. Jones, H. Gong, and D. M. Ionel, "Optimal Combinations of Utility Level Renewable Generators for a Net Zero Energy Microgrid Considering Different Utility Charge Rates," 2019 8th International Conference on Renewable Energy Research and Applications (ICRERA), Brasov, Romania, 2019, pp. 1014-1017, doi: 10.1109/ ICRERA47325.2019.8996529. 


\title{
Optimal Combinations of Utility Level Renewable Generators for a Net Zero Energy Microgrid Considering Different Utility Charge Rates
}

\author{
SPARK Laboratory, Department of Electrical and Computer Engineering, \\ University of Kentucky, Lexington, KY, USA \\ SEvanJones@uky.edu, Huangjie.Gong@uky.edu, dan.ionel@ieee.org
}

Evan S. Jones, Student Member, IEEE, Huangjie Gong, Member, IEEE, and Dan M. Ionel, Fellow, IEEE

\begin{abstract}
High initial investment and the intermittent nature of resources are major challenges for large scale renewable generation. The size of photovoltaic (PV) and wind turbine (WT) farms in the microgrid needs optimized to avoid curtailment and to efficiently meet the demand of a power system. Battery energy storage systems (BESSs) may also be used to improve flexibility. This paper explores the optimal sizing for $\mathrm{PV}$ and wind generators, as well as a BESS at the utility level for a large gridconnected net zero energy (NZE) hybrid microgrid considering characteristics such as initial investment, levelized cost of energy (LCOE), operating costs, net present cost (NPC), and renewable fraction. Multi-objective formal optimizations were formulated as single objective problems with constraints and solved using the HOMER Pro computational engine. Ten optimizations with different utility charge rates are performed using actual data for the load profile, weather, and utility buy-back rates of Glasgow, KY. Simulation results demonstrated that various utility charge rates result in different optimal sizes for the solar PV and the WT farms, as well as for the BESS capacity.
\end{abstract}

Index Terms-Net Zero Energy, Microgrid, HOMER, Battery Energy Storage System, Renewable Energy.

\section{INTRODUCTION}

Renewable energy technologies must become cost competitive with the current low cost, fossil-fueled infrastructure to further encourage their adoption by regions like KY, where renewable net generation is low [1]. Renewable generators like photovoltaic (PV) and wind turbine (WT) must also overcome challenges like resource availability before they are considered for common use. The microgrid structure is a potential solution to the challenges of renewable energy. A proper hybrid microgrid may coordinate multiple energy sources such that demand in the service region is consistently and efficiently met. These systems may be purely grid-connected, islanded from the grid, or may switch between the two modes.

Research that used HOMER Pro to optimize a hybrid microgrid suggests that incorporating WT or PV energy into a power system reduces operating costs and improves system stability, regardless of geographical location or mode [2], [3]. Other studies demonstrate that adding components to the microgrid, such as battery energy storage systems (BESSs) or cycling diesel generators, lessens utility grid dependence and improves efficiency of the renewable energy generation within the system [4], [5]. This leads to reduced overall ex- pense on electricity at the cost of increased initial investment. Methodologies including the reformed electric system cascade analysis (RESCA) technique and the artificial bee colony (ABC) algorithm have been used to optimize a microgrid with HOMER Pro as a benchmark [6], [7].

This study explores the optimal system design and economic viability of a grid-connected hybrid microgrid that could serve the city of Glasgow KY such that the system would be considered net zero energy (NZE). An NZE system produces the same amount of energy as it consumes during a period of an entire year. Ten optimizations were performed using the HOMER Pro microgrid analysis software, each with a different utility charge rate. These ten cases provide a reference for determining when certain microgrid components become economically advantageous in a region like Glasgow as charge rates increase.

This paper presents the effects that the utility charge rate has on the sizing of components within the NZE microgrid, as well as its effects on different economic metrics over a project lifetime of 25 years. As more PV, WT, and BESS capacity were added to the system, grid purchases, cost of electricity, and operating costs decreased. At the same time, initial capital investment increased and renewable fraction, the percentage of energy produced by the renewable generators that is used directly by Glasgow, improved. These findings support that a hybrid microgrid is more cost effective and efficient as more components are introduced.

\section{SySTEM MODELING}

The city of Glasgow, KY is comprised of approximately 7,000 residences as well as some commercial and industrial buildings. The power demand of Glasgow has an average of around $27.54 \mathrm{MW}$ and peaks in July at $48.78 \mathrm{MW}$ according to 2018 data [8]. Demand significantly increases and becomes more variable during the summer due to the air conditioning (Fig. 1). Utility-scale renewable energy generation is adopted in order to serve a demand of that size and variability within an NZE microgrid.

The grid-connected NZE hybrid microgrid had the options of including solar PV arrays, WTs that were modeled after 


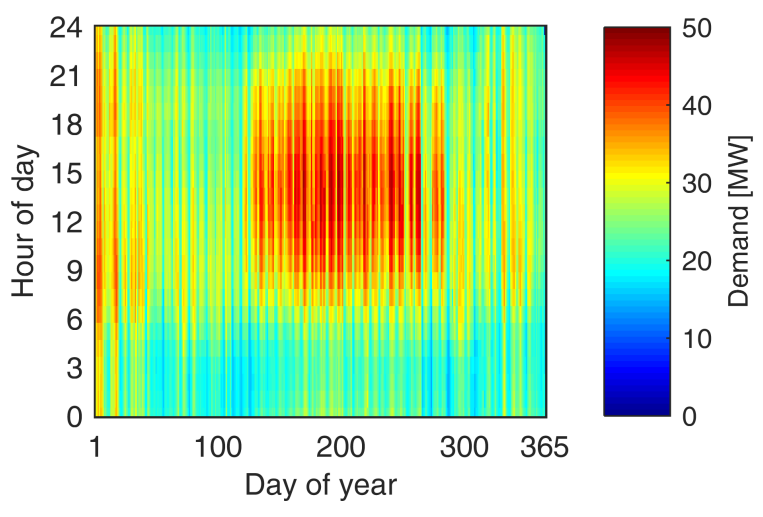

Figure 1. Annual demand characteristics of Glasgow, KY for the year of 2018 represented by hourly statistics.

the Vestas V90-2MW, and a large utility-scale 60MW Liion BESS ranging in capacity from $30 \mathrm{MWh}$ to $510 \mathrm{MWh}$ in increments of $15 \mathrm{MWh}$ (Fig. 2). The PV power output was calculated through HOMER Pro by

$$
P_{P V}=Y_{P V} f_{P V}\left(G_{T} / G_{T, S T C}\right)\left[1+\alpha_{P}\left(T_{c}-T_{c, S T C}\right)\right],
$$

where $Y_{P V}$ is the rated capacity of the PV array; $f_{P V}$, the PV derating factor; $G_{T}$, the solar radiation incident on the PV array; $G_{T, S T C}$, the incident radiation at standard test conditions; $\alpha_{P}$, the temperature coefficient of power; $T_{c}$, the PV cell temperature; $T_{c, S T C}$, the PV cell temperature under standard test conditions [9].

The WT power output is determined by referencing its power curve. It should be noted that the WT hub height is assumed to be 80 meters. Also, the WT power output undergoes a density correction by the equation

$$
P_{W T}=\left(\rho / \rho_{0}\right) *\left(P_{W T, S T P}\right),
$$

where $P_{W T}$ is the corrected WT power output; $\rho$, the actual air density; $\rho_{0}$, the air density at standard temperature and pressure; $P_{W T, S T P}$, the WT power output at standard temperature and pressure.

The microgrid could also purchase energy from the grid when renewable resources were not available. For the ten optimizations, the utility charge rate range was based on the lowest and highest rates in the US. Utility buy-back rates remained the same for each optimization and were based on small power plant and cogeneration time-differential rates set by a regional utility in 2019 [10].

The system was modeled using the local resource data of Glasgow, KY. Wind speed data (Fig. 3) and irradiance data (Fig. 4) were provided by the National Renewable Energy Laboratory (NREL) through HOMER Pro while temperature data (Fig. 5) was provided similarly but from the National Aeronautics and Space Administration (NASA). Irradiance jumps quite noticeably during the summer. Wind speeds are generally low, but still operable for wind turbines like the Vestas V90-2MW.

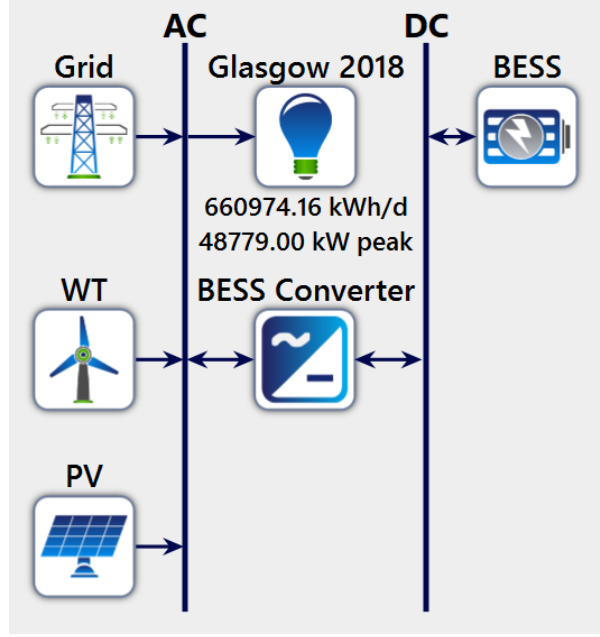

Figure 2. A schematic of the power system as modeled by the HOMER Pro software includes WTs based on the Vestas V90-2MW, solar PV, and a large utility-scale BESS. Power electronics inverters associated with the PV are not explicitly represented, but are included within the PV component.

\section{OPTIMIZATION CRITERIA}

HOMER Pro optimizes the sizing of microgrid components which are PV, WTs, and a BESS in this case. The software considers costs and power ratings of the components, project lifetime, as well as load profile and weather information of the region being served within the simulation. The optimizer then produces multiple "winning" solutions. To ensure that all optimal solutions were NZE, the annual energy purchased from the grid was constrained to $0 \mathrm{kWh}$. The most important characteristic of the solutions to consider is net present cost (NPC), which HOMER Pro bases its optimization algorithm upon. NPC is defined by,

$$
N P C=\left(C_{c}+C_{r}+C_{O \& M}+C_{f}+C_{e}+C_{g}\right)-\left(R_{s}+R_{g}\right),
$$

where $C_{c}$ is capital costs; $C_{r}$, replacement costs; $C_{f}$, fuel costs; $C_{O \& M}$, operation and maintenance costs; $C_{e}$, emissions penalties; $C_{g}$, the costs of buying power from the grid; $R_{s}$, salvage value; $R_{g}$, grid sales revenue.

Solution characteristics also include the total annualized cost which is calculated by

$$
C_{a}=C R F(i, D) * N P C,
$$

where $C R F$ is a function returning the capital recovery factor; $i$, the annual real discount rate; $D$, the project lifetime $(25$ years); $N P C$, the total net present cost.

Another metric is the levelized cost of energy (LCOE), which is defined as

$$
L C O E=\left(C_{a}-C_{b} H\right) / E,
$$

where $C_{a}$ is the total annualized cost of the system; $C_{b}$, the boiler marginal cost; $H$, the total thermal load served; $E$, the total electrical load served. 


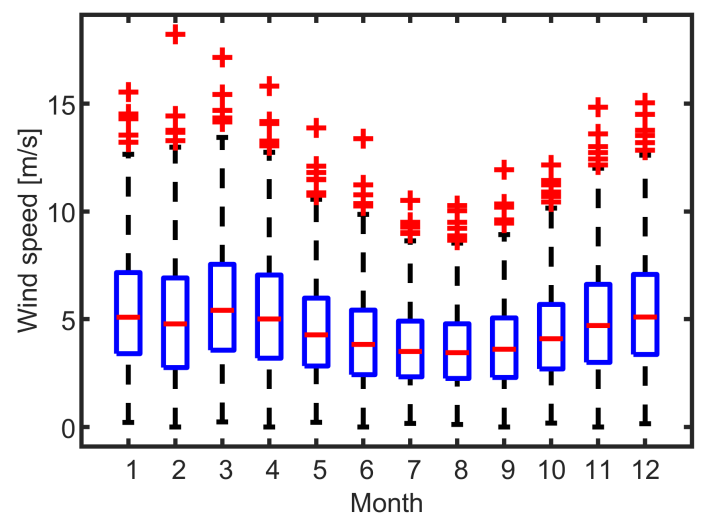

Figure 3. Historic wind speeds of Glasgow, KY for year 2018. The wind speed throughout the entire year is relatively constant.

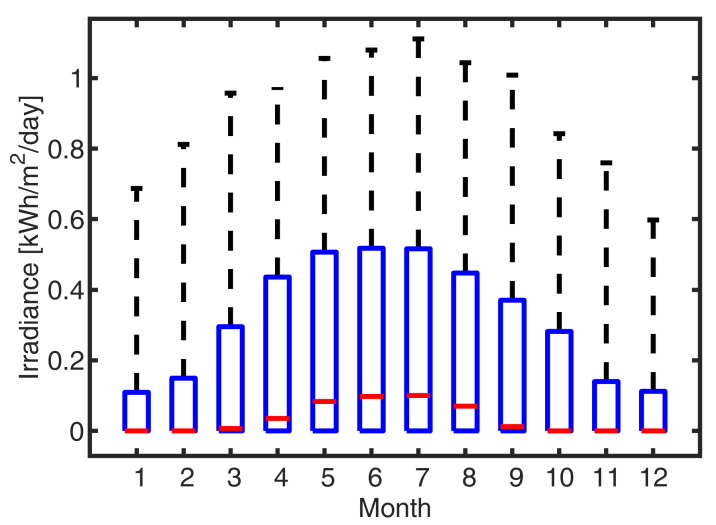

Figure 4. Historic irradiance of Glasgow, KY for year 2018. Summer has the highest average irradiance and largest variation as well.

Operating cost was also used and is calculated as

$$
C_{o}=C_{a}-C_{a, c},
$$

where $C_{a}$ is the total annualized cost and $C_{a, c}$ is the total annualized capital cost.

\section{CAse STudies}

Each of the ten cases included an optimization of the NZE microgrid. The optimizations shared the same component options, system design, utility sell-back rates, weather data, and location. The optimization cases were studied with the charge rate for the first case as $5 \varnothing / \mathrm{kWh}$. The charge rate increased in fixed increments of $5 \phi / \mathrm{kWh}$ and up to $50 \phi / \mathrm{kWh}$ for the tenth case. The off-peak buy-back rate was considered fixed through the year at $2.666 \phi / \mathrm{kWh}$. The on-peak buyback rate for the study was $3.229 \phi / \mathrm{kWh}$ and $2.852 \phi / \mathrm{kWh}$ for the summer and winter, respectively [10]. Different microgrid design characteristics were recorded and compared across the cases with respect to the utility charge rate.

Component sizing of the NZE microgrid differs with various utility charge rates (Fig. 6). Each case included a large PV farm as base generation. WTs were not considered in the

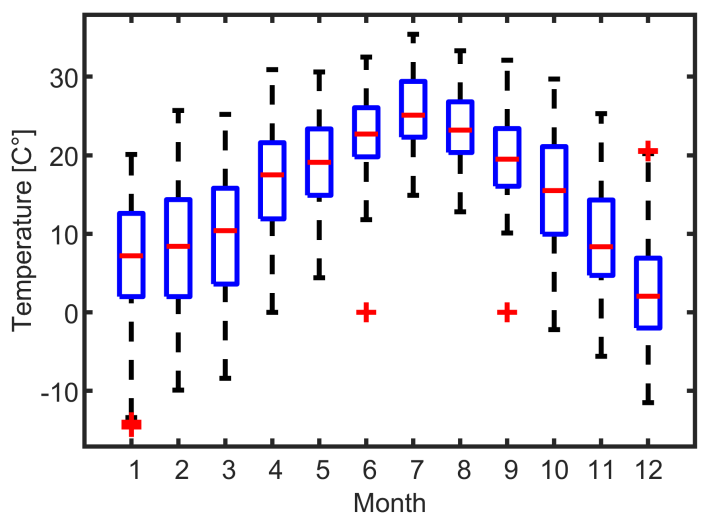

Figure 5. Historic temperatures of Glasgow, KY for year 2017. The temperatures shown represent the typical regional temperatures.

optimal solution until the charge rate was higher or equal to $20 \notin / \mathrm{kWh}$, which then caused a slight dip in PV capacity that soon recovered. Before the BESS was incorporated, the NZE microgrid purchased energy from the grid when renewable generation was unavailable and sold energy to the grid when renewable generation surpassed the demand.

A BESS was not feasible until the charge rate was larger or equal to $25 \phi / \mathrm{kWh}$. After this point, grid purchases plummeted while grid sales slightly dipped and regained traction as PV, WTs, and the BESS increased in size (Fig. 7). Total energy production initially decreased since the system no longer overgenerated as much renewable energy to meet its NZE requirement. It is worth noticing that the total energy production (TP) and total energy consumption (TC) should overlap. The discrepancies happened in cases where BESS was introduced when the utility charge rate was higher than $25 \notin / \mathrm{kWh}$. This happened due to minimum energy distribution to the BESS in the internal models of the HOMER Pro software.

Remaining over-generation was stored in the BESS and used or sold later, making grid purchases less necessary and lowering LCOE (Fig. 8). Although the initial capital costs jumped to accommodate for the addition of the BESS, the increase of NPC was still slowed because reduced grid purchases lessens operating costs (Fig. 9). Using stored renewable energy instead of purchasing from the grid also correlates to a significantly higher renewable fraction.

\section{CONCLUSION}

This paper explored the influence of utility charge rates on the optimal sizes for the utility level components of a grid-connected NZE hybrid microgrid in Glasgow, KY. Ten optimizations were performed using the HOMER Pro microgrid analysis software with the same utility buy-back rates. The results show that utility charge rates affected a variety of microgrid characteristics, such as component sizing, grid exchanges, energy production and consumption, total NPC, LCOE, initial capital costs, operating costs, and renewable fraction. It was determined that an NZE microgrid in rural $\mathrm{KY}$ is most optimal when it is grid-connected without a BESS 


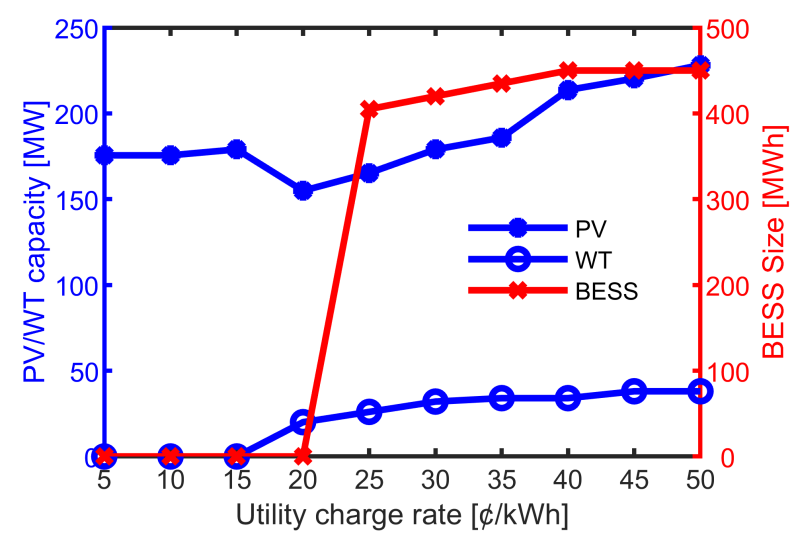

Figure 6. Optimal system component sizes for different utility charge rates PV remained as the base generation for each case. WTs were not considered in the optimal solution until the charge rate was higher than $20 \notin / \mathrm{kWh}$. A BESS did not become viable until the charge rate was at least $25 \notin / \mathrm{kWh}$.

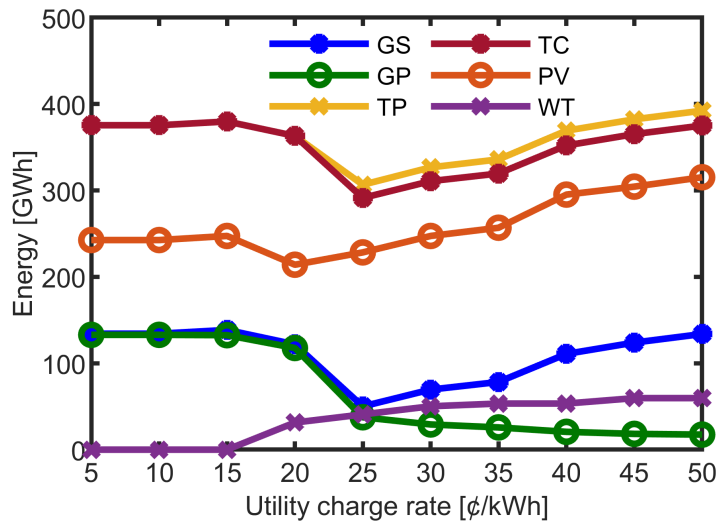

Figure 7. Composition of energy sources influenced by utility charge rates include grid sales (GS), grid purchases (GP), total energy production (TP), total energy consumption (TC), PV energy production (PV), and WT energy production (WT).

until the charge rate is higher or equal to $25 \phi / \mathrm{kWh}$. The optimal system undergoes a drastic change to include a very large utility-scale BESS that reduces costs by avoiding grid purchases at higher utility charge rates.

\section{ACKNOWLEDGMENT}

The direct support of the Schneider Electric Corporation and the University of Kentucky Department of Electrical and Computer Engineering Undergraduate Research Fellowship Program is gratefully acknowledged.

\section{REFERENCES}

[1] "EIA kentucky state profile and energy estimates, 2017," https://www. eia.gov/state/?sid=KY, accessed: $2019-08-01$.

[2] K. Adetunji, O. Akinlabi, and M. Joseph, "Developing a microgrid for tafelkop using homer," in 2018 International Conference on Advances in Big Data, Computing and Data Communication Systems (icABCD). IEEE, 2018, pp. 1-6.

[3] T. Adefarati, R. C. Bansal, and J. J. Justo, "Techno-economic analysis of a pv-wind-battery-diesel standalone power system in a remote area," The Journal of Engineering, vol. 2017, no. 13, pp. 740-744, 2017.

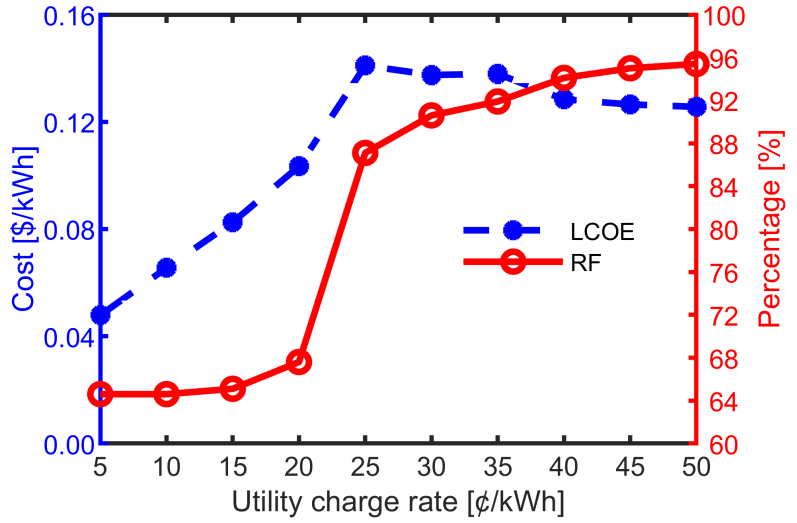

Figure 8. LCOE and renewable fraction (RF) combinations for different utility charge rates. The RF improved as the charge rate increased. LCOE began to decrease once the BESS was added to the optimal design at $25 \phi / \mathrm{kWh}$. The $\mathrm{RF}$ experienced a drastic increase once the BESS was introduced.

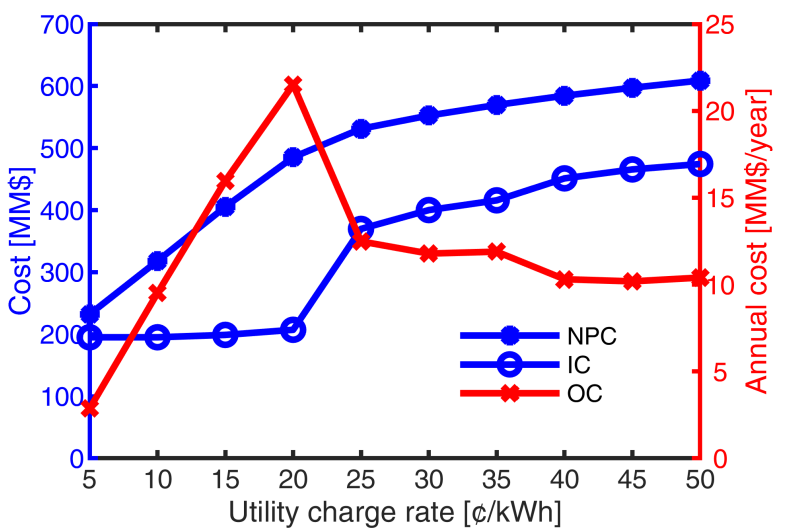

Figure 9. Combinations of net present cost (NPC), initial capital (IC) cost, and operating cost (OC) for different utility charge rates. NPC and IC increased as the charge rate became higher. OC began to decrease at the $25 \phi / \mathrm{kWh}$ when the BESS was added. The addition of the BESS slowed the increase of the NPC and caused a jump in initial capital investment.

[4] T. Hennessy et al., "European town microgrid and energy storage application study," in 2013 IEEE PES Innovative Smart Grid Technologies Conference (ISGT). IEEE, 2013, pp. 1-6.

[5] Y. Bhandari, S. Chalise, J. Sternhagen, and R. Tonkoski, "Reducing fuel consumption in microgrids using pv, batteries, and generator cycling," in IEEE International Conference on Electro-Information Technology, EIT 2013. IEEE, 2013, pp. 1-4.

[6] S. Singh and S. C. Kaushik, "Optimal sizing of grid integrated hybrid pv-biomass energy system using artificial bee colony algorithm," IET Renewable Power Generation, vol. 10, no. 5, pp. 642-650, 2016.

[7] R. Singh and R. C. Bansal, "Optimization of an autonomous hybrid renewable energy system using reformed electric system cascade analysis," IEEE Transactions on Industrial Informatics, vol. 15, no. 1, pp. 399-409, 2018.

[8] H. Gong, V. Rallabandi, M. L. McIntyre, and D. M. Ionel, "On the optimal energy controls for large scale residential communities including smart homes," in Proceedings, IEEE ECCE 2019, Baltimore, MD, 5p, (Oct 2019).

[9] "HOMER pro calculations," https://www.homerenergy.com/products/ pro/docs/3.11/homers_calculations.html, accessed: 2019-08-01.

[10] "KU rates and tariffs, 2019," https://lge-ku.com/regulatory/ rates-and-tariffs, accessed: 2019-05-19. 